Article

\title{
Stochastic Unit Commitment and Optimal Power Trading Incorporating PV Uncertainty
}

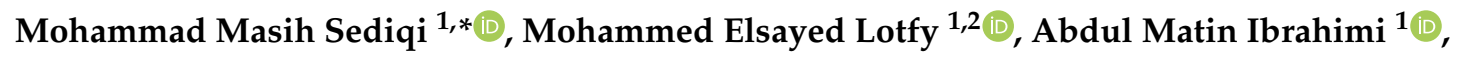 \\ Tomonobu Senjyu ${ }^{1}$ (D) and Narayanan. $K^{3}$ (D) \\ 1 Department of Electrical and Electronics Engineering, University of the Ryukyus, Okinawa 903-0213, Japan \\ 2 Department of Electrical Power and Machines, Zagazig University, Zagazig 44519, Egypt \\ 3 Department of Electrical and Electronics Engineering, SASTRA Deemed University, Thanjavur-613401, India \\ * Correspondence: mohammadmasiih@gmail.com
}

Received: 1 August 2019; Accepted: 15 August 2019; Published: 20 August 2019

check for updates

\begin{abstract}
This paper focuses on the optimal unit commitment (UC) scheme along with optimal power trading for the Northeast Power System (NEPS) of Afghanistan with a penetration of $230 \mathrm{MW}$ of PV power energy. The NEPS is the biggest power system of Afghanistan fed from three main sources; 1. Afghanistan's own power generation units (three thermal units and three hydro units); 2 . imported power from Tajikistan; 3. imported power from Uzbekistan. PV power forecasting fluctuations have been handled by means of 50 scenarios generated by Latin-hypercube sampling (LHS) after getting the point solar radiation forecast through the neural network (NN) toolbox. To carry out the analysis, we consider three deterministic UC and two stochastic UC cases with a two-stage programming model that indicates the day-ahead UC as the first stage and the intra-day operation of the system as the second stage. A binary-real genetic algorithm is coded in MATLAB software to optimize the proposed cases in terms of thermal units' operation costs, import power tariffs, as well as from the perspective of the system reliability risks expressed as the reserve and load not served costs. The results indicate that in the deterministic UC models, the risk of reserve and load curtailment does exist. The stochastic UC approaches including the optimal power trading are superior to the deterministic ones. Moreover, the scheduled UC costs and reserves are different from the actual ones.
\end{abstract}

Keywords: stochastic unit commitment; optimal power trading; Afghanistan; PV uncertainty; binary-real-coded genetic algorithm

\section{Introduction}

Afghanistan, a country with around $30 \%$ of its population having accessibility to the utility grid [1], is now rebuilding its energy sector with the help of the international community with a focus on providing sustainable energy to its people. Several renewable energy development projects are being undertaken by the government of Afghanistan. The utilization of these resources is also encouraged by introducing the problem of air pollution of the country since Afghanistan is amongst the top 10 countries most affected by indoor air pollution [2]. Given the low levels of energy generation and accessibility, Afghanistan's contribution to global $\mathrm{CO}_{2}$ emissions is small. Moreover, while the country has abundant renewable energy sources (RES), still it is an electricity importing nation [3].

Despite several benefits including low economic costs and zero environmental impacts, RES are adding fluctuation and uncertainty to power systems. Because of these characteristics, the increasing level of renewable sources input to power systems makes their operation a challenging task. As an example, in the problem of unit commitment (UC), an unexpected reduction in renewable power production might lead to load shedding (i.e., energy not served or reserve not served), due to the technical constraints of thermal units that would not be able to compensate the forecast error of RES. 
On the other side, a large upward forecast error in renewable power generation may result in an undesired waste of renewable and clean energy when the committed thermal units are running at their cost-effective production levels. In order to investigate the effects of RES (photovoltaic power generation (PV)) on the Afghan power systems' control and operation, we take the Northeast Power System (NEPS) of Afghanistan, the largest power system in the country, as a case study and consider UC (including the optimal power trading since the power system has electricity importations) as a typical optimization problem, which plays a prominent role in power system operation planning aiming at specifying which generating units are the most cost effective to be dispatched, so as to meet the power demand and reserve requirement.

Many research efforts have been concentrated on an efficient UC scheme such as the simulated annealing algorithm (SAA) [4,5], evolutionary programming (EP) [6], the ant colony system (ACS) [7], mixed-integer linear programming (MILP) [8-10], the genetic algorithm (GA) [11-13], particle swarm optimization (PSO) [14], the binary-real-coded artificial bee colony (BRABC) algorithm [15], and many others. None of the studies mentioned above considered the effect of PV power on system operation; instead, they only focused on thermal generating units. To take the renewable power effect into account, some studies and models have been considered to solve the thermal unit commitment scheme incorporating renewable power. In [16], a chance-constrained two-stage (CCTS) stochastic program taking the uncertain wind power output into account was studied. In this method, the chance constraint validates wind power's minimum utilization by setting a risk level, which restricts the chance that a large amount of wind power may be curtailed. The influence of different wind power forecasting, reserve requirement, as well as different UC formulations on system operation is presented in [17]. In order to handle wind power uncertainties in the UC optimization problem, [18] proposed a hybrid method. In the suggested model, the optimal unit stage is optimized in the first stage, and the final power generation scheduling based on a scenario with the best merit is calculated in the second step. This method uses the quantum-inspired binary gravitational search algorithm (QBGSA) along with scenario analysis. The authors in [19] incorporated the uncertainty integration of different sources such as solar, wind, load, and generator outages in stochastic security-constrained unit commitment (SCUC). In this study, system cost and different reserve plans are presented from the system economic and reliability points of view. A new clustering scheme for the wind-hydro-thermal unit commitment problem taking wind power uncertainty into account was introduced by [20]. In this method, to decrease computational time, similar scenarios are combined so as to generate a new reduced set including focal scenarios with some probability. In order to solve the nonlinear optimization problem, the weighted improved crazy particle swarm optimization technique is implemented along with the pseudocode-based technique. The results indicated that with a pumped storage power plant and stochastic UC, the operation cost and risk level can be minimized. The research paper [21] proposed a binary artificial sheep algorithm for the UC of a hybrid system (thermal units, wind, solar, and pumped hydro-energy storage (PHES) power plants). In this study, the influence of solar and wind power uncertainty on UC was examined by looking at different solar and wind power forecasting error levels. In addition, the impact of PHES was analyzed, indicating that PHES can increase system stability, as well as diminish renewable energy uncertainty. To solve UC and economic dispatch (ED) considering the uncertainty of wind generation, a probabilistic scheme was analyzed in [22]. The probability distribution of the variables was found in a discrete form, and the near optimal scheduling of the system was specified by combining the proposed scheme with a priority list method. Another research work [23] also studied wind power uncertainty on the UC problem taking PHES into account. Considering the aforementioned available research works, the main contributions of this paper are summarized as follows:

- Implementation of the UC optimization problem along with the optimal power trading considering PV output power uncertainty on a large practical power system, which are vital issues from the economic and reliability points of view. 
- Applying the proposed optimization problems to keep the connection between physicallyfunctioning power system and theoretical simulations to indicate the actual market operation and constraints.

- The majority of the research works considered the fitness function to be the total operation cost of thermal units (for some studies, plus the reserve and energy not served); however, in the current study, as the practical power system suggests, import power tariffs are also analyzed.

- Most of the research work focused only on the wind power uncertainty integration in the UC optimization issue, but no research can be observed that has worked on just PV power uncertainty integration in optimal unit commitment and at the same time including optimal power trading.

- Instead of traditional Monte Carlo simulation, Latin-hypercube sampling along with Cholesky decomposition (LHS-CD) is used to generate forecasted PV scenarios.

\section{Afghanistan's Solar Energy Potential}

Afghanistan possess adequate renewable sources; however, they are not uniformly disseminated throughout the country, except solar energy sources. Western regions of Afghanistan have the availability of wind sources, the whereas central, northern, southern, and eastern regions are suitable for small and micro hydro power plants. Solar energy exists with almost an indistinguishable amount everywhere in the country [24], as shown in Figure 1 [25]. Afghanistan is located in a sunny belt, is blessed with many sunshine hours and high insolation levels, and is ideally located to benefit from solar energy technologies. The country averages 300 days of the sunshine per year. The mean global irradiation falling on the horizontal surface is about $6.5 \mathrm{kWh}$ per $\mathrm{m}^{2}$ per day; this amounts to about 3000 sunshine hours and $2.37 \mathrm{MWh} / \mathrm{m}^{2} /$ year. Energy radiated from the Sun is about $6.6 \times 10^{10} \mathrm{~kW}$, and the possible solar energy potential for the country is $2.22 \times 10^{8} \mathrm{~kW}$. The sun shines on average for $10 \mathrm{~h}$ per day [26-29]. This amount of solar energy in Afghanistan cannot only fulfill the present annual energy requirements at home, but it can be exported to other countries as well.

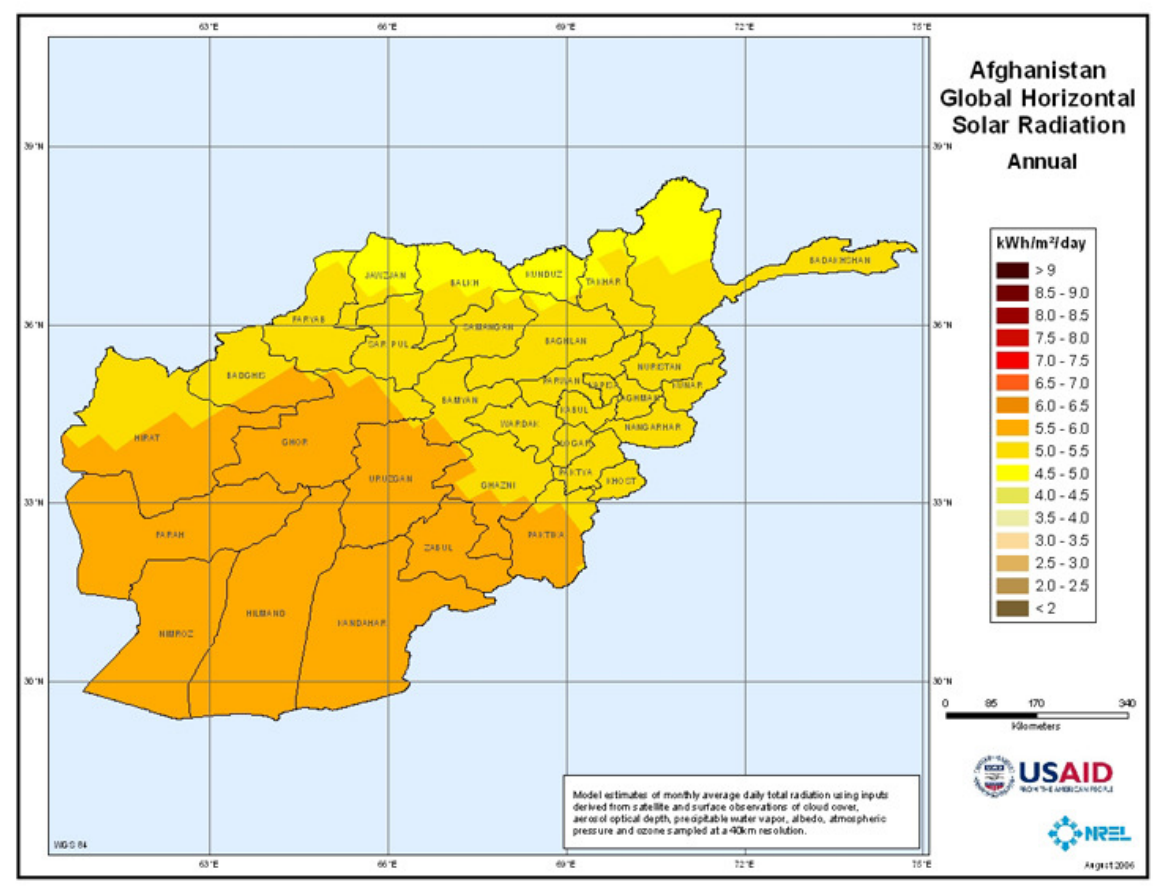

Figure 1. Afghanistan solar radiation map [25]. 


\section{Prediction and Scenario Formulation}

\subsection{Point Forecast Using a Neural Network}

To consider the impacts of PV electric power uncertainty in optimal UC and power trading schemes (stochastic models), at first, scenarios were generated based on the point predicted solar radiation and the forecast error. In this study, a neural network (NN) implemented in the Neural Network Toolbox (nftool) of MATLAB was used to predict the point solar radiation. The NN was trained by utilizing the back-propagation algorithm providing with data (temperature, humidity, and wind speed of Kabul City, Afghanistan) from April 2011 to April 2015 as inputs and the solar radiation as the output $[30,31]$. Then, the mean absolute error (MAE) was calculated from the forecasted solar radiation obtained for each hour in May 2015 (Figure 2). The computed MAE was 25\%. The forecasted result of solar radiation in Kabul City, Afghanistan, on 10 May 2017 is shown in Table 1.

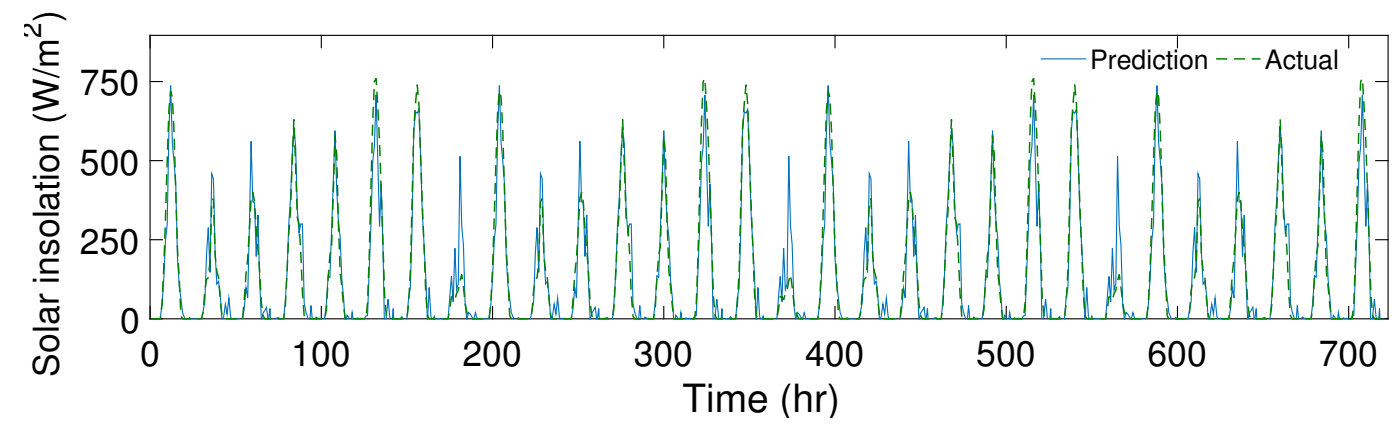

Figure 2. Solar radiation forecast results for May 2015, Kabul City, Afghanistan.

Table 1. Predicted solar insolation.

\begin{tabular}{ccccccccccccc}
\hline Time $(\mathrm{h})$ & 1 & 2 & 3 & 4 & 5 & 6 & 7 & 8 & 9 & 10 & 11 & 12 \\
$I_{t}\left(\mathrm{~W} / \mathrm{m}^{2}\right)$ & 0 & 0 & 0 & 0 & 0 & 0 & 50 & 145 & 270 & 405 & 593 & 687 \\
Time $(\mathrm{h})$ & 13 & 14 & 15 & 16 & 17 & 18 & 19 & 20 & 21 & 22 & 23 & 24 \\
$I_{t}\left(\mathrm{~W} / \mathrm{m}^{2}\right)$ & 600 & 520 & 420 & 260 & 65 & 18 & 0 & 0 & 0 & 0 & 0 & 0 \\
\hline
\end{tabular}

\subsection{Scenario Generation}

As mentioned before, the calculated MAE of solar forecasting was between $-25 \%$ and $+25 \%$. Then, scenarios were generated between a level of high solar radiation of $125 \%$ and low solar radiation of $75 \%$. Many available literature works used Monte Carlo $[16,19,32]$ and Latin-hypercube sampling (LHS) $[20,33]$ simulation techniques for renewable energy uncertainty representation. The main difference between these two approaches is the number of iterations needed to produce an input distribution through sampling precisely. Monte Carlo simulation requires a large number of samples to approximate an input distribution, while LHS converges faster, thus requiring fewer samples. Therefore, in this research work, LHS along with Cholesky decomposition (LHS-CD) was introduced to generate scenarios within the given band at every hour. The inclusion of Cholesky decomposition [33] was to decrease unwanted correlations between samples of random variables. The 50 scenarios generated for $24 \mathrm{~h}$ on 10 May 2017 for Kabul City, Afghanistan, using the suggested method are indicated in Figure 3 (PV electric power was calculated using Equation (13)). 


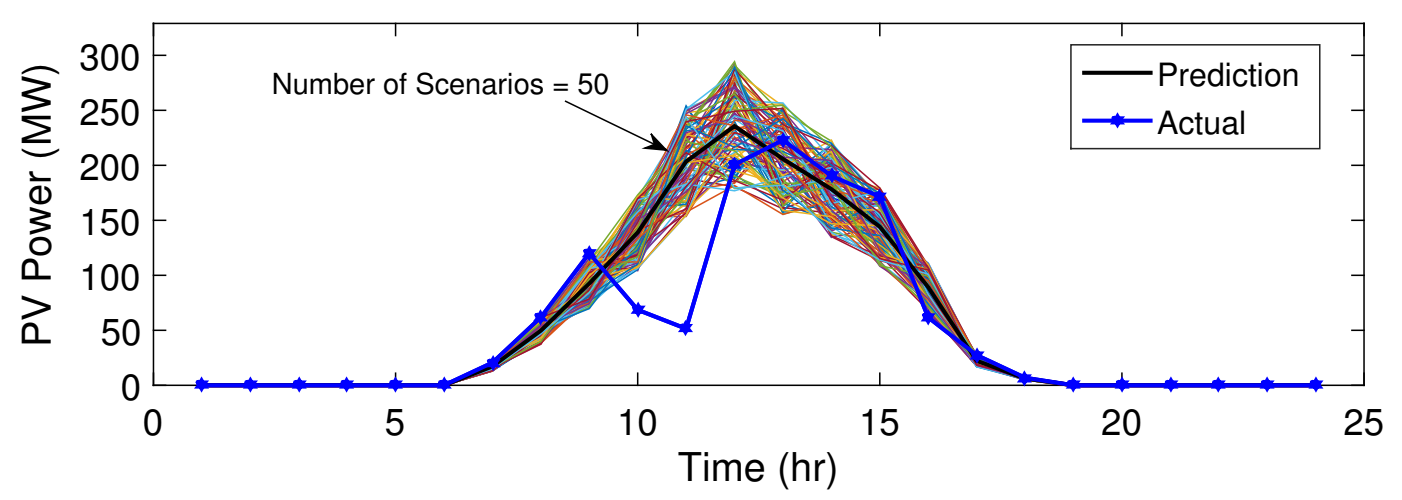

Figure 3. PV scenarios for uncertainty representation.

\section{UC and Optimal Power Trading Problems Formulation}

As was discussed in the Introduction section, in recent years, a large amount of RES, specifically PV electric power, has been introduced into the Afghan power systems. This originates from the fact that there is massive potential for solar energy in Afghanistan, as well as the need and demand for electric energy of poor and unfortunate people. Afghanistan imports $78 \%$ of electrical energy from its neighbor countries (Uzbekistan, Turkmenistan, Tajikistan, and Iran), and the remaining $22 \%$ is from its own generation from thermal and hydro units [34]. Furthermore, the utilization of this clean and environmentally-friendly energy source is further encouraged by considering the issue of air pollution in the country.

As the country is experiencing its initial stages of integrating PV technology into its existing power systems, it is very important to have a research work investigating the influences of PV power uncertainty for its power systems' optimal operation and control. Therefore, in the current paper, the NEPS of Afghanistan, which is supplied by existing hydropower and diesel projects of the country and imported power from its two neighboring countries (Tajikistan and Uzbekistan), is selected, and the optimization problems of UC and power trading are solved.

\subsection{Objective Function}

As PV and hydro power plants do not consume fuel, they are the first selection. In the present study, the purpose of solving UC and optimal power trading for the proposed system with PV uncertainty is to minimize the expected operation cost (fuel cost and start-up cost) of thermal units and the expected tariffs of import powers, as well as to maximize the system reliability expressed as the penalty terms of expected load not served (LNS) and reserve not served (RNS) costs, subject to some constraints. Thus, the objective function can be expressed as follow:

where:

$$
\begin{aligned}
T C & =\sum_{s=1}^{N s} \omega_{s}\left\{\sum_{i=1}^{N G} \sum_{t=1}^{T} F C_{i}\left(P G_{i, t}^{s}\right) U_{i t}+\sum_{z=1}^{Z} \sum_{t=1}^{T} c_{z} \times P F_{z, t}^{s}+\sum_{t=1}^{T}\left(C_{l n s} \times L N S_{t}^{s}+C_{r n s} \times R N S_{t}^{s}\right)\right\} \\
& +\sum_{i=1}^{N G} \sum_{t=1}^{T}\left\{S C_{i, t}\left(1-U_{i, t-1}\right) U_{i, t}\right\}
\end{aligned}
$$

where:

$T C$ is the total expected cost;

$s$ indicates scenarios $s=1, \ldots, N s$;

$\omega$ is the probability of scenario $s$; 
$i$ shows thermal generators, $i=1, \ldots, N G$;

$t$ is the index of time intervals in the planning horizon, $t=1, \ldots, T$;

$F C_{i}\left(P G_{i, t}^{s}\right)$ is the fuel cost function of the $i^{\text {th }}$ thermal unit at time $t$ in scenario $s$;

$P G_{i, t}^{s}$ is the output power of thermal unit $i$ at hour $t$ in scenario $s$;

$U_{i, t}$ is the on/off $[0,1]$ status of the $i^{\text {th }}$ thermal unit at time $t$;

$z$ is the index for countries from which Afghanistan imports, $z=1, \ldots, Z$;

$c_{z}$ is the cost of importing power for Afghanistan from country $z$;

$P F_{z, t}^{s}$ is the power imported by Afghanistan from country $z$ at hour $t$;

$C_{\text {lns }}$ is the cost of load not served;

$L N S_{t}^{s}$ is the load not served at time $t$ in scenario $s$;

$C_{r n s}$ is the cost of reserve not served;

$R N S_{t}^{s}$ is the reserve not served at hour $t$ in scenario $s$;

$S C_{i, t}$ is the start-up cost of the $i^{\text {th }}$ thermal unit at hour $t$.

The fuel cost function $F C_{i}\left(P G_{i, t}^{s}\right)$ is given by:

$$
F C_{i}\left(P G_{i, t}^{s}\right)=a_{i}+b_{i} P G_{i, t}^{s}+c_{i}\left(P G_{i, t}^{s}\right)^{2}
$$

where $a_{i}, b_{i}, c_{i}$ are the fuel cost coefficients of the $i^{\text {th }}$ thermal unit.

The start-up cost of the $i^{\text {th }}$ thermal unit depending on the continuous off time of the unit before starting-up is given by the following equation:

$$
S C_{i, t}=\left\{\begin{array}{c}
S C_{i}^{\text {hot }}: M D T_{i} \leq T_{i, t}^{\text {off }} \leq M D T_{i}+T_{i}^{\text {cold }} \\
S C_{i}^{\text {cold }}: T_{i, t}^{\text {off }} \geq M D T_{i}+T_{i}^{\text {cold }}
\end{array}\right\}
$$

where:

$S C_{i}^{\text {hot }}$ is the hot start-up cost of the $i^{\text {th }}$ thermal unit;

$M D T_{i}$ is the minimum down time of the $i^{\text {th }}$ thermal unit;

$T_{i, t}^{o f f}$ is the duration of the $i^{\text {th }}$ thermal generator being continuously off;

$T_{i}^{\text {cold }}$ is the cold start-up hour of the $i^{\text {th }}$ thermal unit;

$S C_{i}^{\text {cold }}$ is the cold start-up cost of thermal unit $i$.

The objective function (2) is constrained by the following equalities and inequalities.

\subsection{Thermal Units' Output Power Limit}

The active power generation of each committed thermal unit must be within its minimum and maximum limits:

$$
P G_{i, \min } U_{i, t} \leq P G_{i, t}^{s} \leq P G_{i, \max } U_{i, t}
$$

where $P G_{i, \min }$ and $P G_{i, \max }$ are the minimum and maximum generation limits of thermal unit $i$.

\subsection{Power Trading Limits}

The import power of Afghanistan from country $z$ (Tajikistan or Uzbekistan) is restricted by the minimum and maximum power export capacity of the country $z$.

$$
P F_{z, \min } \leq P F_{z, t}^{s} \leq P F_{z, \max }
$$

\subsection{System Power Balance Constraint}

The sum of generated power from online thermal units, import power, the output power of hydro units, and PV should be equal to the load demand minus the LNS of the system. 


$$
\sum_{i=1}^{N G} P G_{i, t}^{s} U_{i, t}+\sum_{z=1}^{Z} P F_{z, t}^{s}+\sum_{j=1}^{J} P_{j, t}+P_{P V, t}^{s}=P L_{t}-L N S_{t}^{s}
$$

where:

$j$ indicates hydropower plants, $j=1, \ldots, J$;

$P_{j, t}$ is the power output of hydro unit $j$ at hour $t$;

$P_{P V, t}^{s}$ is the generated power of $\mathrm{PV}$ at time $t$ in scenario $s$;

$P L_{t}$ is the power demand of the system at hour $t$.

\subsection{System Spinning Reserve Constraint}

To maintain system reliability, adequate spinning reserves are necessary.

$$
\sum_{i=1}^{N G} U_{i, t}\left[P G_{i, \max }-P G_{i, t}^{s}\right] \geq R_{t}^{s}-R N S_{t}^{s}
$$

where $R_{t}^{s}$ is the spinning reserve of the system at hour $t$ in scenario $s$.

\subsection{Thermal Units' Minimum up and down Time Constraints}

Due to operational constraints, once a thermal unit is committed/decommitted, it must remain stable for a minimum period before a transition:

$$
\begin{gathered}
\left(T_{i, t}^{\text {on }}-M U T_{i}\right)\left(U_{i,(t-1)}-U_{i, t}\right) \geq 0 \\
\left(T_{i, t}^{\text {off }}-M D T_{i}\right)\left(U_{i, t}-U_{i,(t-1)}\right) \geq 0
\end{gathered}
$$

where:

$$
\begin{gathered}
T_{i, t}^{o n}=\left(T_{i,(t-1)}^{o n}+1\right) U_{i, t} \\
T_{i, t}^{o f f}=\left(T_{i,(t-1)}^{o f f}+1\right)\left(1-U_{i, t}\right)
\end{gathered}
$$

and where:

$T_{i, t}^{o n}$ is the total up-time of the $i^{\text {th }}$ unit;

$M U T_{i}$ is the minimum up-time of unit $i$.

\subsection{PV Power Generation}

$\mathrm{PV}$ power generation for actual solar radiation and forecasted solar radiation is calculated based on the following equation:

$$
P p v=\eta_{p v} \cdot A_{p v} \cdot I(t)
$$

where $\eta_{p v}$ indicates the PV panels' efficiency, $A_{p v}$ is the total area occupied by the PV panels in $\mathrm{m}^{2}$, and $I(t)$ is the hourly solar insolation in $\mathrm{MW} / \mathrm{m}^{2}$.

\section{Binary-Real Coded Genetic Algorithm}

In the present research work, a binary-real genetic algorithm (GA) [13] is coded in MATLAB software to find the optimal value of the objective function (2) constrained by (5)-(12). In the proposed algorithm, the binary-coded GA specifies thermal units' scheduling (on/off status), and the real-coded GA finds the power dispatch of thermal units and optimal power imports. The difference between the methodology of [13] and the approach used in this research is that the earlier included only deterministic UC, while the study under consideration deals with the stochastic UC including power trading in which the number of decision variables increases exponentially with the increasing number of scenarios; thus, it becomes a more difficult and complex optimization issue. 


\subsection{Initialization}

In GA, decision variables are coded by a string structure called chromosomes. Initially, the GA is structured to generate randomly a set of chromosomes called a population $(Q)$ within their predefined domain. The scheduling of thermal units is assigned the value of zero or one with the same probability, while their output power is selected to be a random real value between their minimum and maximum power limits. In addition, the import power from Tajikistan and Uzbekistan is also chosen to have random amounts between their minimum and maximum export capacities.

\subsection{Repairing Procedures}

With the stochastic UC, the number of decision variables increases exponentially with the increasing number of scenarios; therefore, for any algorithm, it is very difficult to maintain units and system constraints, especially when random initial populations are generated, thus requiring the utilization of some repairing procedures to be taken into account. The following mechanisms, which have already been considered [11-13,35], are now introduced into the study. The repairing procedures aim to repair the solutions that violate the given constraints.

The minimum up and down constraint of thermal units were handled by adjusting units' on and off status, respectively. If $M U T_{i}>T_{i, t}^{o n}$, then the commitment status of the unit is extended to the next hours until the constraint is satisfied. Accordingly, if $M U T_{i}>T_{i, t}^{o f f}$, then the off status of the unit is updated by committing the unit in the off hours between two committed states.

LNS and RNS of (7) and (8) are calculated accordingly after the completion of UC scheduling and economic thermal units' dispatches, as well as the optimal import power.

It should be mentioned that besides the implementation of the above procedures after the initialization, they are also applied after the crossover and mutation operations.

\subsection{Calculation of the Objective Function}

The initial population passing through the repairing mechanisms is put into the fitness function (2), and their values are calculated and the best ones stored.

\subsection{Selection}

The selection operator aims to create multiple copies of good solutions and omit weak solutions, while keeping the population size constant. To do so, a number of ways and methods are available [36]. The tournament selection approach [36] (with the tournament size $=2$ ) is applied herein in which tournaments are played between two random solutions and the solution with a better fitness value is selected and put into the mating pool.

\subsection{Crossover}

The selection procedure generates more copies of strong solutions, but it does not create any new solutions (offspring population); instead, the crossover and mutation operators are assigned for this purpose. The crossover operator is used to create two or more offspring from two or more parent solutions chosen during the selection process. The same as the selection operator, there exist some types of crossover procedures, and within this paper, the two-point crossover operator was applied [36]. With a predefined crossover probability $\left(P_{c}\right)$, two random parent solutions were picked from the mating pool, and some portions of them (either the middle or two ends) were exchanged to create two new offspring solutions.

\subsection{Mutation}

In order to keep the diversity in the population that helps the search towards global optima, the mutation operator was needed [36]. The mutation operator randomly altered a string with a mutation probability $\left(P_{m}\right)$ to generate a better string. 


\section{Simulation Conditions}

The simplified diagram of the NEPS of Afghanistan simulated for the optimal UC and power trading taking PV output power uncertainty into account is depicted in Figure 4. The penetration capacity of PV electric power was assumed to be $230 \mathrm{MW}$. The system power demand, thermal units' data, and import power parameters are indicated in Figure 5 and Tables 2 and 3, respectively. In Table 2, TG is the thermal generator. The power system also includes three hydropower plants, each with available capacities of $100 \mathrm{MW}, 66 \mathrm{MW}$, and $22 \mathrm{MW}$. The cost of RNS was $\$ 1100 / \mathrm{MWh}$, and the cost of LNS was $\$ 3500 / \mathrm{MW}$ h. To compensate the forecasted error of PV power generation, the basic spinning reserve is considered to be $10 \%$ of the load. The following five case studies were conducted to show the impacts of PV electric power and different UC modelings and various spinning reserve needs, as well as to indicate the effectiveness of the proposed method.

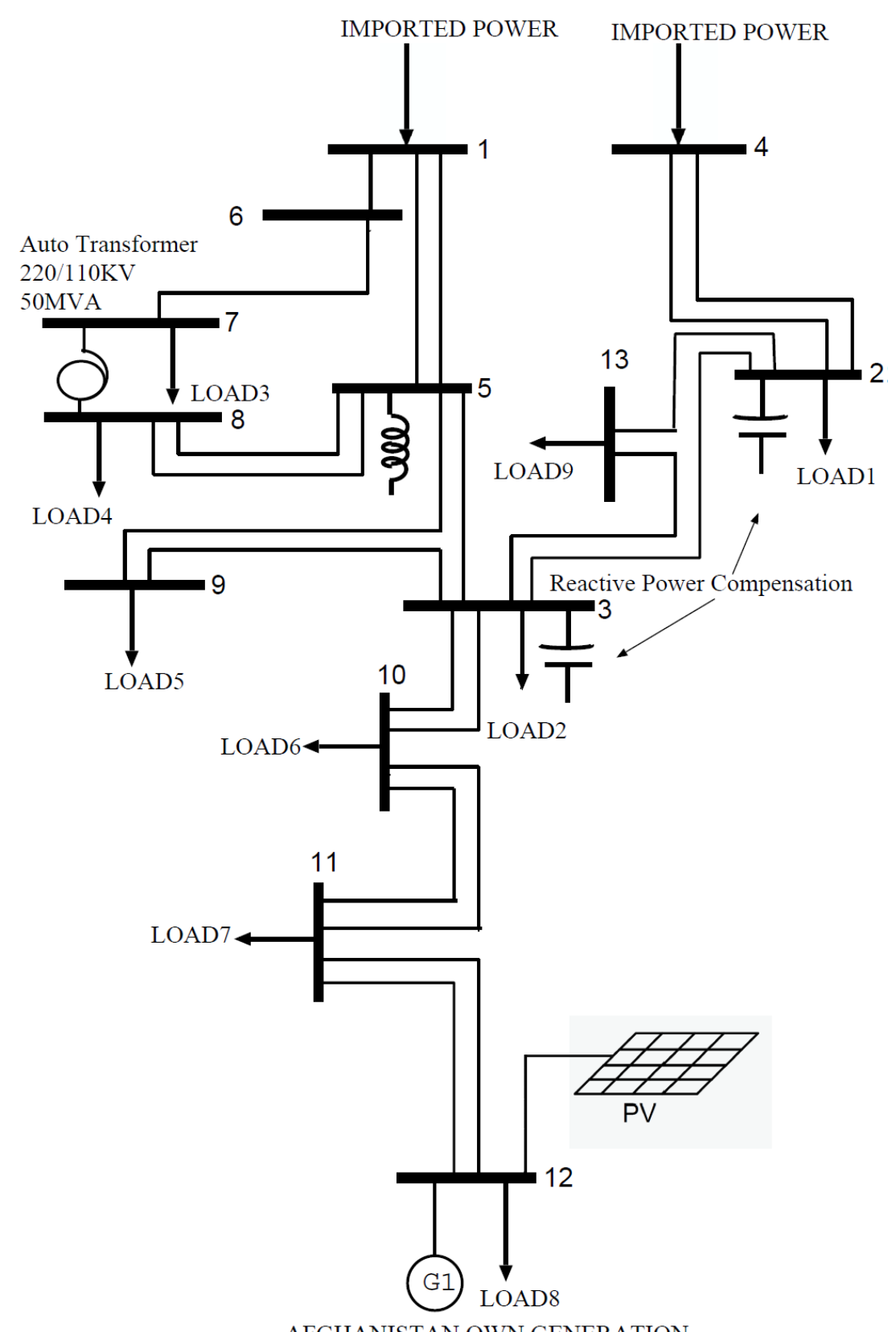

Figure 4. The simplified diagram of the Northeast Power System (NEPS) of Afghanistan [3]. 
- Case 1: The PV power is not injected into the power system; the existing three thermal generating units, three hydro units, and import power from Tajikistan and Uzbekistan are selected to meet the power demand (deterministic UC and optimal electricity trading).

- $\quad$ Case 2: The PV power point forecast is used along with the power generating system of Case 1.

- Case 3: The same as Case 2, all the power-generating units are connected, including PV forecasted power, but this time, the perfect forecast of $\mathrm{PV}$ generation is considered.

- Case 4: This case takes into account 50 predicted PV scenarios generated with the method described in the Prediction and Scenario Formulation section. The basic spinning reserve was assumed as $10 \%$ of the load demand (stochastic UC and optimal power trading).

- Case 5: The stochastic UC of case 4 with increasing the reserve requirement from $10 \%-15 \%$ of the system power demand.

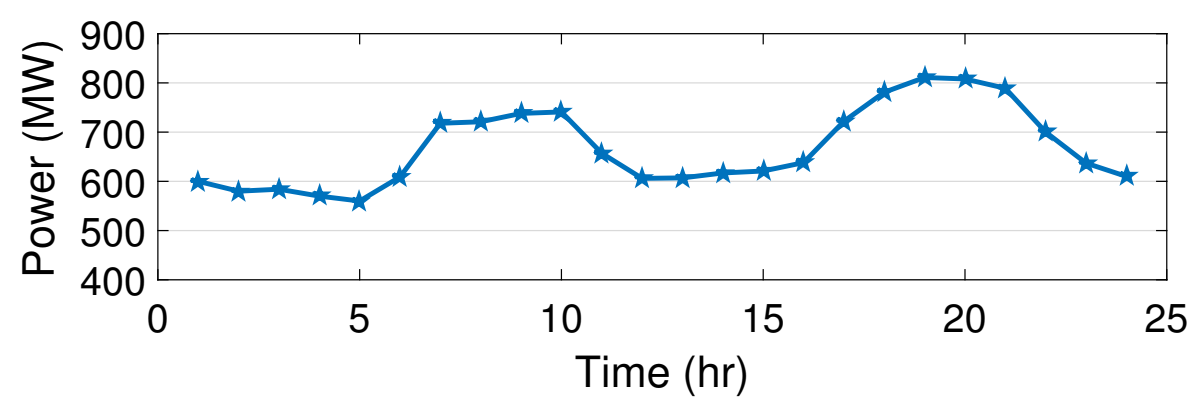

Figure 5. Power demand of the NEPS of Afghanistan [37,38].

Table 2. Thermal units' data $[37,38]$. TG, thermal generator.

\begin{tabular}{llll}
\hline & TG-1 & TG-2 & TG-3 \\
\hline $\mathrm{PG}_{\mathrm{i}, \max }(\mathrm{MW})$ & 105 & 22 & 23 \\
$\mathrm{PG}_{\mathrm{i}, \min }(\mathrm{MW})$ & 15 & 5 & 5 \\
$a_{i}(\$ / \mathrm{h})$ & 680 & 660 & 665 \\
$b_{i}(\$ / \mathrm{MWh})$ & 16.5 & 25.92 & 27.27 \\
$c_{i}\left(\$ / \mathrm{MW}^{2} h\right)$ & 0.00211 & 0.00413 & 0.00222 \\
$M U_{i}(\mathrm{~h})$ & 4 & 1 & 1 \\
$M U_{i}(\mathrm{~h})$ & 4 & 1 & 1 \\
$S C_{i}^{\text {hot }}(\$)$ & 560 & 30 & 30 \\
$S C_{i}^{\text {cold }}(\$)$ & 1120 & 60 & 60 \\
$T_{i}^{\text {cold }}(\mathrm{h})$ & 4 & 0 & 0 \\
$T_{i, 0}(\mathrm{~h})$ & 4 & 1 & -1 \\
\hline
\end{tabular}

Table 3. Import power parameters $[37,38]$.

\begin{tabular}{lll}
\hline Parameters & Tajikistan & Uzbekistan \\
\hline$P F_{z, \max }$ & 300 & 300 \\
$P F_{z, \min }$ & 0 & 0 \\
$c_{z}(\$ / \mathrm{MWh})$ & 20 & 60 \\
\hline
\end{tabular}

Simulations were run based on a two-stage programming in which the on/off states of thermal units and power dispatch (thermal units' economic dispatch and import powers) were run in sequence. The simulation period $\mathrm{T}$ was selected by dividing one day into $24 \mathrm{~h}$. In the day-ahead stochastic cases, UC were achieved by minimizing the total expected cost expressed in (2) as per the 50 scenarios of PV generation (for the deterministic cases, (2) considers only one scenario, PV point forecast).

For both UC modelings (deterministic and stochastic), in the second step (intra-day), an economic dispatch was made by setting the values of the variables representing the status of the thermal units found at the day-ahead stage. This stage minimized the total cost considering only one scenario: the actual PV power known on that respective day. 


\section{Simulation Results and Discussions}

The objective function (2) subject to the constraints (5)-(12) was solved for each case, and the simulation results (Figures 6-12) are discussed as follow:

- Case 1: This case was considered to analyze the impact of not integrating PV power generation into the proposed power system when dealing with deterministic UC and optimal power trading. The results for both day-ahead UC and intra-day operation included the total cost $T C=\$ 366,940$ (fuel cost $=\$ 86,533$, start-up cost $=\$ 1360$, import power tariff $=\$ 279,050$ ). As can be observed from Figure $6 \mathrm{a}$, this case had the highest cost amongst all day-ahead UC costs, because more thermal units needed to be online (Figure 7) and more power was imported from Tajikistan and Uzbekistan (Figure 8a) to recover the unavailable output power of PV. Moreover, because of the large penalty from RNS and LNS, the operating reserve for the day-ahead UC was over the basic spinning reserve lines (Figure 9), meaning that the cost associated with the reserve and load curtailments was zero. Due to zero PV power penetration, the intra-day operation available reserve (Figure 10) was the same as the scheduled available reserve (Figure 9).

- Case 2: As PV electric power was added to the power system, the total cost (Figure 6a) decreased to $T C=\$ 310,340$ (fuel cost $=\$ 81,340$, start-up cost $=\$ 1270$, import power tariff $=\$ 227,730$ ), since compared to Case 1, it required less thermal units to be turned on (Figure 7) and less power to be imported from the two neighboring countries (Figure 8a). In addition, as the forecasted power was more than the actual power, hence among the deterministic cases, Case 2 had the least $T C$ leading to lower available reserve capacity (Figure 9) and a high risk of reserve curtailment for the intra-day operation, as described below. For the intra-day operation (Figure 6b), despite the substantial contribution from import powers (Figure 8b), because of the reserve curtailment happening at Hour 11 due to the high deviation between the actual PV generation and the predicted power, Case 2 incurred the most enormous cost $T C=\$ 402,400$ (fuel cost $=\$ 78,133$, start-up cost $=\$ 1270$, import power tariff $=\$ 261,120$, reserve curtailment cost $=\$ 61,875$ ). There was one very important point to be mentioned: although a much lower available reserve capacity existed from Hours 17-21, the risks of reserve curtailment did not exist in these hours, and this was because of the unavailability of the PV power in these hours.

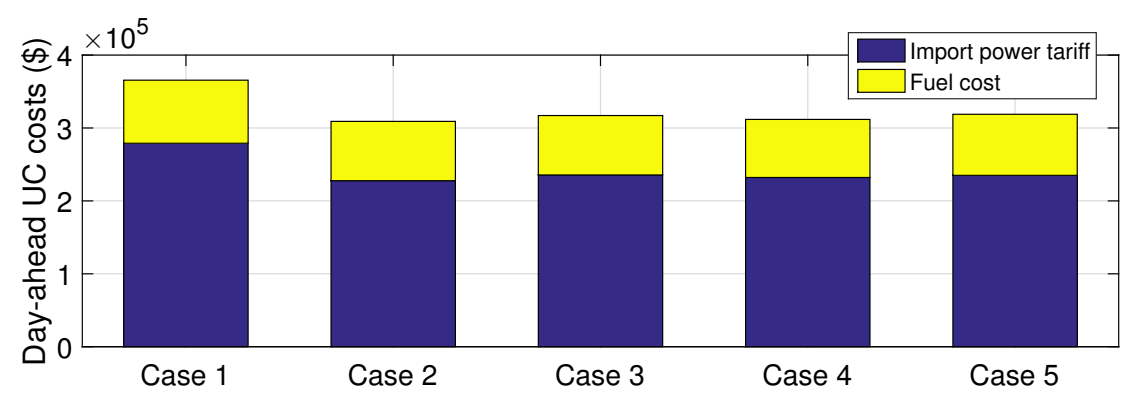

(a)

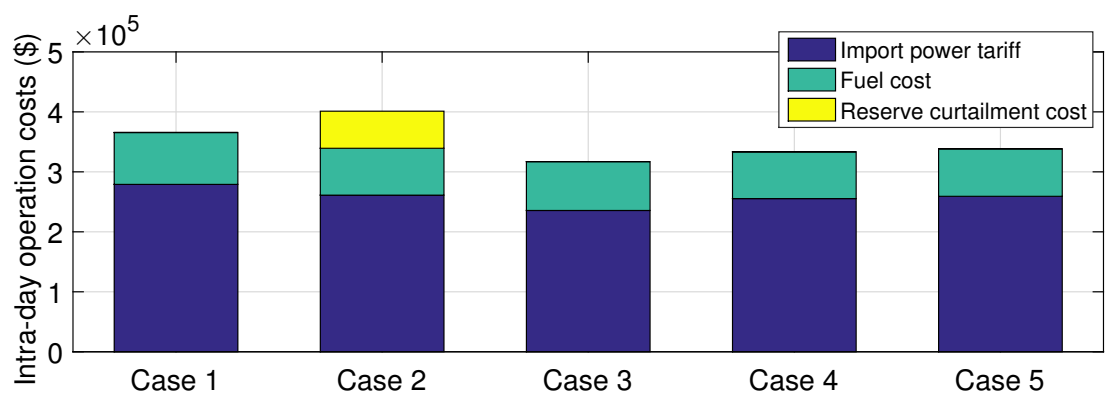

(b)

Figure 6. Deterministic and stochastic unit commitment (UC) and operation costs. (a) Day-ahead UC costs. (b) Intra-day operation costs. 


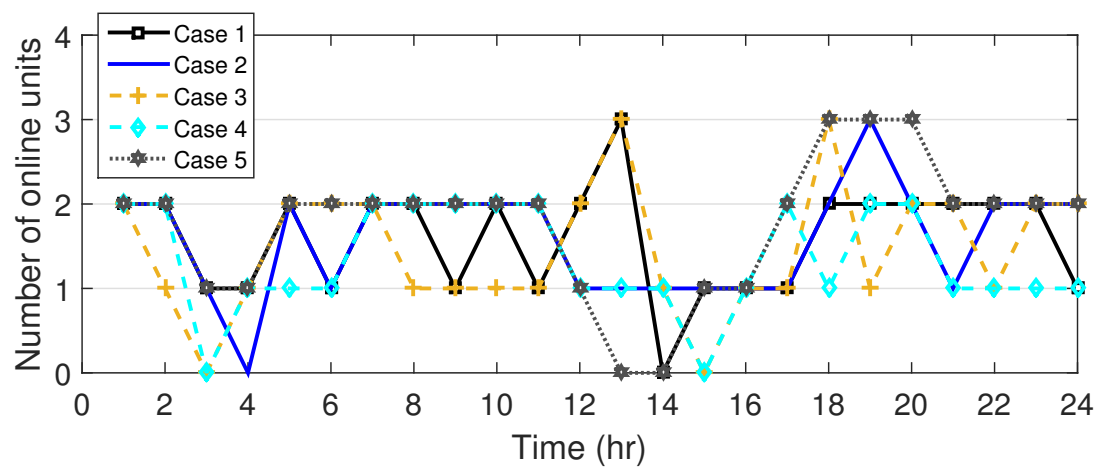

Figure 7. Number of thermal online units.

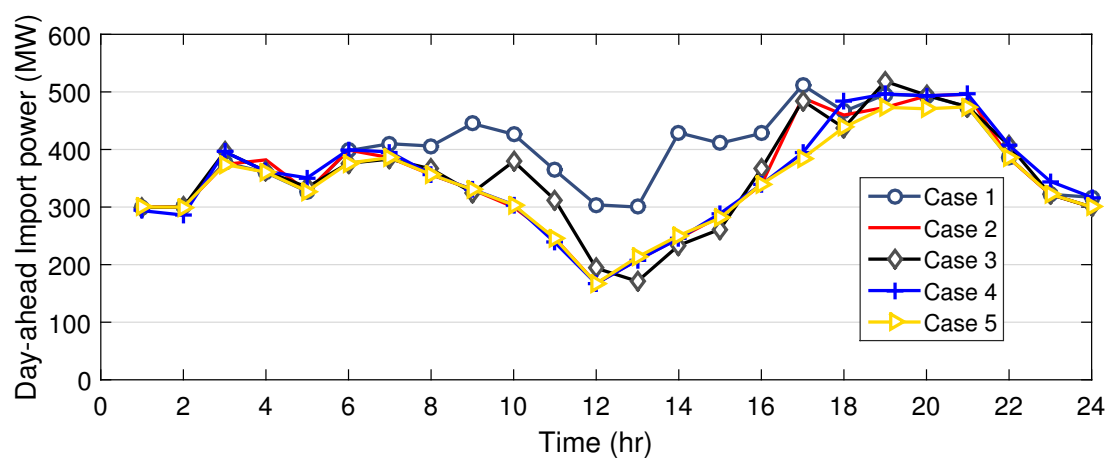

(a)

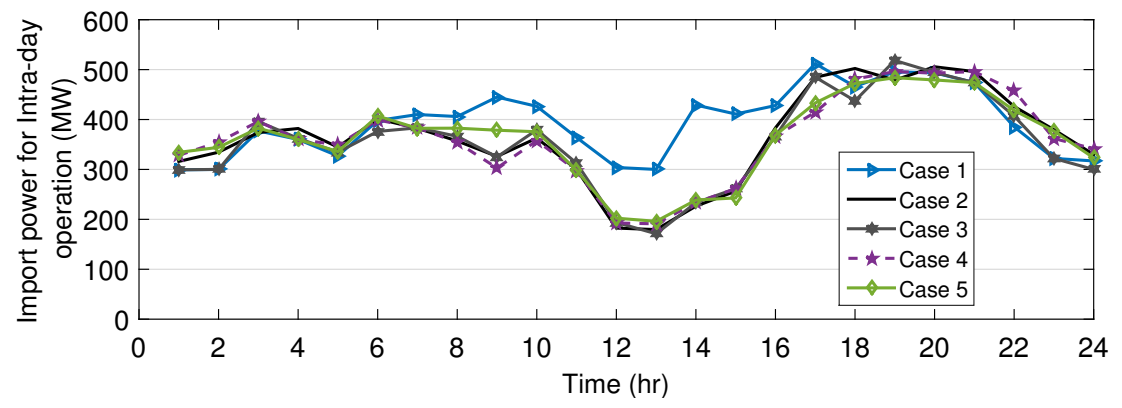

(b)

Figure 8. Optimal power trading based on day-ahead UC and intra-day operation. (a) Import power based on day-ahead UC. (b) Import power as per intra-day operation.

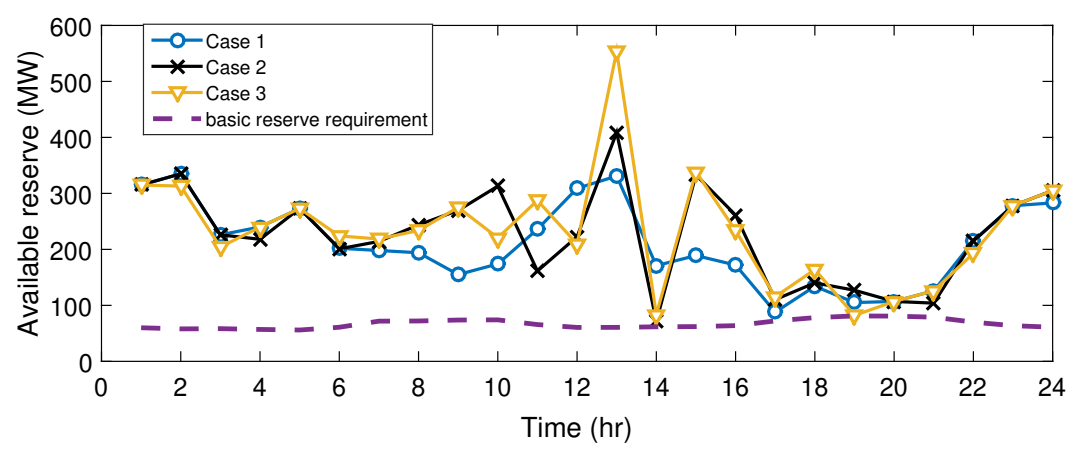

Figure 9. Scheduled day-ahead available operating reserve for Case 1-Case 3. 


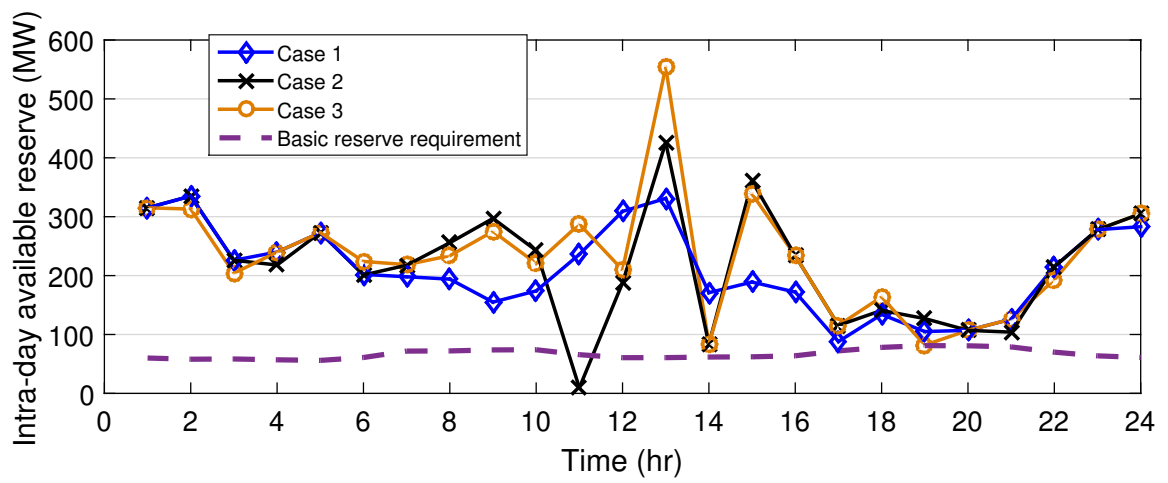

Figure 10. Intra-day available operating reserve for Case 1-Case 3.

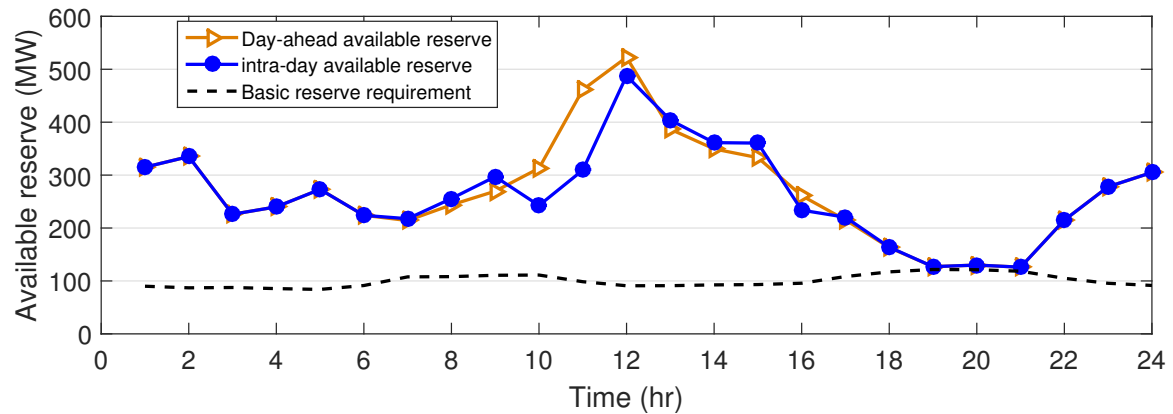

Figure 11. Day-ahead UC and intra-day operation available reserve of Case 4.

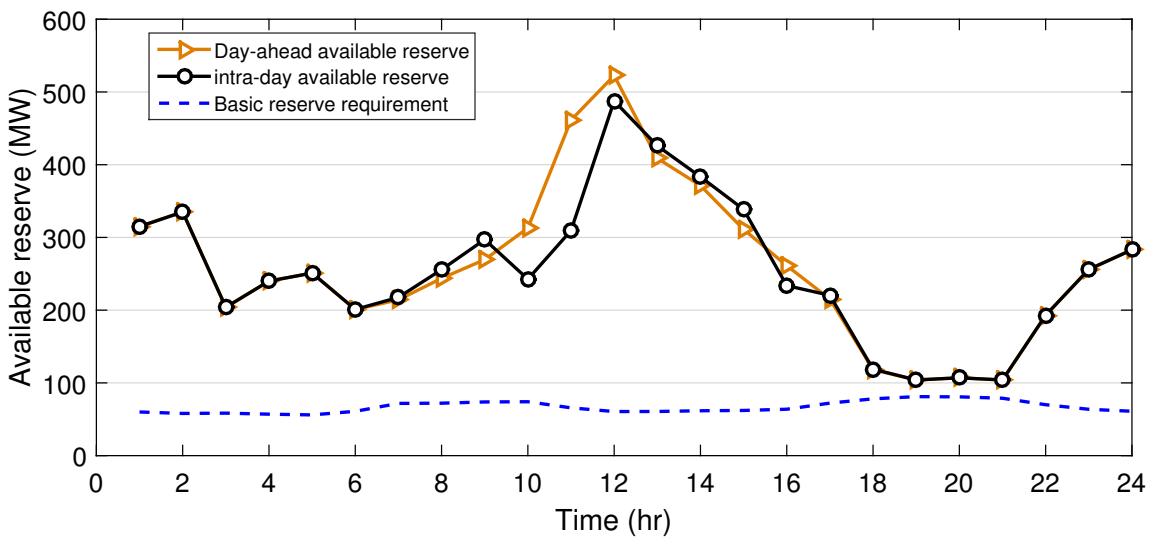

Figure 12. Day-ahead UC and intra-day operation available reserve of Case 5.

- Case 3: The actual PV generation was used in Case 3; therefore, the day-ahead UC and intra-day operation costs were the same (no load and reserve curtailment happened). Furthermore, as discussed in Case 2, the actual PV power was less than the forecast generation; thus, for the day-ahead UC costs (Figure 6a), Case 3 incurred a higher total cost TC $=\$ 318,430$ (fuel cost $=\$ 81,495$, start-up cost $=\$ 1360$, import power tariff $=\$ 235,580)$ than Case 2 , resulting in extra thermal unit commitment (Figure 7) and much power imported (Figure 8a). However, among the intra-day operation costs (Figure 6b), it incurred the lowest cost since no reserve and load curtailment occurred (Figure 10).

- Case 4: The 50 scenarios of forecasted PV power were used to capture its uncertainty. For the day-ahead UC (Figure 6a), the total expected cost was TC $=\$ 313,050$ (expected fuel cost $=\$ 79,635$, start-up cost $=\$ 1300$, expected import power tariff $=\$ 232,120)$. In this case, more thermal units were needed to be turned on to manage different PV power scenarios compared to the deterministic Cases 1 and 2, which considered only one scenario (Figure 7). Furthermore, due to the large penalty from $R N S$, the available reserve was above the basic spinning reserve 
(Figure 11). Moreover, for the intra-day operation (Figure 6b), the total cost was $T C=\$ 334,740$ (fuel cost $=\$ 78,047$, start-up cost $=\$ 1300$, expected import power tariff $=\$ 255,390$ ), for which, unlike Case 2, the reserve curtailment cost was zero, also leading the available reserve for the intra-day operation to be over the basic spinning reserve requirement (Figure 11), which depicts the superiority of Case 4 (stochastic UC with inclusion of the optimal power trading).

- Case 5: In order to investigate the impact of different reserve needs and to further show the superiority of the stochastic UC including the optimal power trading, Case 5 with the reserve requirement of $15 \%$ of the power demand was studied. For the day-ahead UC (Figure 6a), the total expected cost $T C=\$ 320,020$ (expected fuel cost $=\$ 83,759$, start-up cost $=\$ 1210$, expected import power tariff $=\$ 235,051$ ) was higher than the stochastic Case 4 with the basic reserve requirement, therefore leading to more thermal units being turned on (Figure 7) and more power being imported (Figure 8a). In addition, for the intra-day operation (Figure 6b), the total cost was $T C=\$ 339,670$ (fuel cost $=\$ 79,291$, start-up cost $=\$ 1210$, import power tariff $=\$ 259,170$ ), in which the reserve curtailment cost was zero, and the same as the stochastic Case 4, the available reserve was over the reserve need of the system (Figure 12).

\section{Conclusions}

In this study, the NEPS of Afghanistan, which includes optimal electricity trading, as well, was selected, and the day-ahead UC and intra-day operation for the different UC modelings and reserve requirements were analyzed. Unlike the previous studies, in this research work, besides implying the UC optimization scheme, the optimal power trading was also investigated. In addition, in most of the studies, the objective function is the total operation cost of thermal units; however, in this paper, as the practical problem of optimal operation suggests, imports power tariffs were also added, which further increased the complexity of the system optimization. Moreover, the coordination between a physically-functioning power system and simulation results was kept to represent the actual market operation, and for the uncertainty representation of PV, the Latin-hypercube Sampling along with the Cholesky decomposition (LHS-CD) was used instead of traditional Monte Carlo simulation.

Five case studies were analyzed and discussed from the perspective of the system economy and reliability. A binary-real GA was coded in MATLAB software for the optimization of each case study. The results for the day-ahead UC indicated that as Case 1 considered no PV power penetration, hence the total cost $T C=\$ 366,940$ of Case 1 was the largest. Case 2 used the PV point forecast, which was higher than the actual forecast; hence, Case 2 obtained the least cost of $T C=\$ 310,340$. For the intra-day operation cost, in contrast to the least day-ahead UC cost, Case 2 obtained the largest cost $T C=\$ 402,400$ due to the high reserve curtailment cost. Obviously, Case 3 with perfect forecast had the lowest cost of $T C=\$ 318,430$ among the intra-day operation costs since no reserve and load curtailment happened. Case 4 considered 50 scenarios of predicted PV power with the basic spinning reserve equal to $10 \%$ of the load demand; hence, for the day-ahead UC, the total expected cost $T C=\$ 313,050$ of Case 4 was higher than Case 2, which used only one scenario. This was due to more online scheduling of units, compared to the deterministic Case 2, to handle the predicted PV power scenarios. However, for the intra-day operation, Case 4 had a total cost of $T C=\$ 334,740$, for which, unlike Case 2, the reserve curtailment cost was zero, leading the available reserve for the intra-day operation to be over the basic reserve requirement. This result indicated the superiority of the stochastic Case 4. Case 5 took into account 50 scenarios of forecasted PV power with the spinning reserve equal to $15 \%$ of the system load demand. Therefore, compared to Case 4 , the day-ahead and intra-day operation costs increased to $\$ 320,020$ and $\$ 339,670$, respectively. The same as Case 4 , the reserve curtailment cost was zero. The results of Case 5 indicated that the total cost of the system was increased by raising the reserve requirement of the system.

For future work, as Afghanistan is located between energy surplus regions (Central Asian countries) and an energy deficit area (Pakistan) and also has abundant RES, this can be exploited not only to meet its power demand, but also it can export to Pakistan as well. Therefore, for future work, 
Pakistan as electricity deficit country will also be included in the model. Furthermore, the effect of a storage system such as PHES will also be investigated. In addition, the cost minimization along with profit maximization are to be explored.

Author Contributions: M.M.S.: conceptualization, formal analysis, data curation, methodology, investigation, software, validation, writing of the original draft, writing review and editing; M.E.L.: formal analysis, methodology, software, validation writing review and editing. A.M.I.: software and formal analysis; T.S.: project administrator, supervision, validation, and funding acquisition; N.K.: writing of the original draft and validation.

Conflicts of Interest: The authors declare no conflict of interest.

\section{References}

1. Ahmadzai, S.; McKinna, A. Afghanistan electrical energy and trans-boundary water systems analyses: Challenges and opportunities. Energy Rep. 2018, 4, 435-469. [CrossRef]

2. Global Alliance for Clean Cookstoves. Available online: http://www.cleancookstoves.org/countries/asia/ afghanistan.html (accessed on 10 February 2018).

3. Sediqi, M.M.; Furukakoi, M.; Lotfy, M.E.; Yona, A.; Senjyu, T. Optimal economical sizing of grid-connected hybrid renewable energy system. J. Energy Power Eng. 2017, 11, 244-253.

4. Mantawy, A.H.; Magid, Y.L.A.; Selim, S.Z. A simulated annealing algorithm for unit commitment. IEEE Trans. Power Syst. 1998, 13, 197-204. [CrossRef]

5. Simopoulos, D.N.; Kavatza, S.D.; Vournas, C.D. Reliability constrained unit commitment using simulated annealing. IEEE Trans. Power Syst. 2006, 21, 1699-1705. [CrossRef]

6. Juste, K.A.; Kita, H.; Tunaka, E.; Hasegawa, J. An evolutionary programming solution to the unit commitment problem. IEEE Trans. Power Syst. 1999, 14, 1452-1459. [CrossRef]

7. Simon, S.P.; Padhy, N.P.; Anand, R.S. An ant colony system approach for unit commitment problem. Electr. Power Energy Syst. 2006, 28, 315-323. [CrossRef]

8. Carrión, M.; Arroyo, J.M. A computationally efficient mixed-integer linear formulation for the thermal unit commitment problem. IEEE Trans. Power Syst. 2006, 21, 1371-1378. [CrossRef]

9. Frangioni, A.; Gentile, C.; Lacalandra, F. Sequential lagrangian-MILP approaches for unit commitment problems. Electr. Power Energy Syst. 2011, 33, 586-593. [CrossRef]

10. Viana, A.; Pedroso, J.P. A new MILP-based approach for unit commitment in power production planning. Electr. Power Energy Syst. 2013, 44, 997-1005. [CrossRef]

11. Sun, L.; Zhang, Y.; Jiang, C. A matrix real-coded genetic algorithm to the unit commitment problem. Electr. Power Syst. Res. 2006, 76, 716-728. [CrossRef]

12. Kumar, V.S.; Mohan, M.R. Solution to security constrained unit commitment problem using genetic algorithm. Electr. Power Energy Syst. 2010, 32, 117-125. [CrossRef]

13. Datta, D. Unit commitment problem with ramp rate constraint using a binary-real-coded genetic algorithm. Appl. Soft Comput. 2013, 13, 3873-3883. [CrossRef]

14. Yuan, X.; Su, A.; Nie, H.; Yuan, Y.; Wang, L. Unit commitment problem using enhanced particle swarm optimization algorithm. Soft Comput. 2011, 15, 139-148. [CrossRef]

15. Chandrasekarana, K.; Hemamalini, S.; Simon, S.P.; Padhy, N.P. Thermal unit commitment using binary/real coded artificial bee colony algorithm. Electr. Power Syst. Res. 2012, 84, 109-119. [CrossRef]

16. Wang, Q.; Guan, Y.; Wang, J. A chance-constrained two-stage stochastic program for unit commitment with uncertain wind power output. IEEE Trans. Power Syst. 2012, 27, 206-215. [CrossRef]

17. Wang, J.; Botterud, A.; Bessa, R.; Keko, H.; Carvalho, L.; Issicaba, D.; Sumaili, J.; Miranda, V. Wind power forecasting uncertainty and unit commitment. Appl. Energy 2011, 88, 4014-4023. [CrossRef]

18. Ji, B.; Yuan, X.; Li, X.; Huang, Y.; Li, W. Application of quantum-inspired binary gravitational search algorithm for thermal unit commitment with wind power integration. Energy Convers. Manag. 2014, 87, 589-598. [CrossRef]

19. Quan, H.; Srinivasan, D.; Khambadkone, A.M.; Khosravi, A. A computational framework for uncertainty integration in stochastic unit commitment with intermittent renewable energy sources. Appl. Energy 2015, 152, 71-82. [CrossRef]

20. Shukla, A.; Singh, S.N. Clustering based unit commitment with wind power uncertainty. Energy Convers. Manag. 2016, 111, 89-102. [CrossRef] 
21. Wang, W.; Li, C.; Liao, X.; Qin, H. Study on unit commitment problem considering pumped storage and renewable energy via a novel binary artificial sheep algorithm. Appl. Energy 2017, 187, 612-626. [CrossRef]

22. Lujano-Rojas, J.M.; Osório, G.J.; Catalão, J.P.S. New probabilistic method for solving economic dispatch and unit commitment problems incorporating uncertainty due to renewable energy integration. Electr. Power Energy Syst. 2016, 78, 61-71. [CrossRef]

23. Min, Z.; Kun, Z.; Liang, W. Study on unit commitment problem considering wind power and pumped hydro energy storage. Electr. Power Energy Syst. 2014, 63, 91-96.

24. Central Statistics Organization of Afghanistan. March 2019. Available online: www.cso.gov.af/en (accessed on 12 March 2019).

25. National Renewable Energy Laboratory (NREL). Afghanistan Resource Maps and Toolkit. Available online: http:/ / www.nrel.gov/international/raAfghanistan.html (accessed on 5 May 2018).

26. Ministry of Energy and Water. Renewable Energy Department. potential map-Solar. Islamic Republic of Afghanistan. Available online: http:/ /www.red-mew.gov.af/media/complete-download-list/ (accessed on 15 May 2018).

27. Alamyar, K.M. Renewable Energy for Sustainable Development; Economic Policy Directorate; Ministry of Economy, April 2014. Available online: https://econpapers.repec.org/paper/ekd006666/7828.htm (accessed on 15 August 2019).

28. Musleh, A.J. Renewable Energy Department. Ministry of Energy and Water. In Proceedings of the SAARC Workshop on Application of on-Grid Biogas Technologies, Kabul, Afghanistan, 16-17 May 2016.

29. Delawari, Q. Investment Opportunities in Energy Sector in Afghanistan. CEO, DABS Presentation; 24 October 2016. Available online: https://www.carecprogram.org/uploads/2016-EIF-PresentationSession1-AFG-1.pdf (accessed on 10 March 2019).

30. Kiartzis, S.J.; Bakirtzis, A.G.; Petridis, V. Short-term load forecasting using neural networks. Electr. Power Syst. Res. 1995, 33, 1-6. [CrossRef]

31. Panapakidis, I.P. Clustering based day-ahead and hour-ahead bus load forecasting models. Int. J. Electr. Power Energy Syst. 2016, 80, 171-178. [CrossRef]

32. Furukakoi, M.; Adewuyi, O.B.; Matayoshi, H.; Howlader, A.M.; Senjyu, T. Multi objective unit commitment with voltage stability and PV uncertainty. Appl. Energy 2018, 228, 618-623. [CrossRef]

33. Yu, H.; Chung, C.Y.; Wong, K.P.; Lee, H.W.; Zhang, J.H. Probabilistic load flow evaluation with hybrid Latin Hypercube Sampling and Cholesky Decomposition. IEEE Trans. Power Syst. 2009, 24, 661-667. [CrossRef]

34. Sediqi, M.M.; Howlader, H.O.R.; Ibrahimi, A.M.; Danish, M.S.S.; Sabory, N.R.; Senjyu, T. Development of renewable energy resources in Afghanistan for economically optimized cross-border electricity trading. Aims Energy 2017, 5, 691-717. [CrossRef]

35. Gjorgiev, B.; Kančev, D.; Čepin, M.; Volkanovski, A. Multi-objective unit commitment with introduction of a methodology for probabilistic assessment of generating capacities availability. Eng. Appl. Artif. Intell. 2015, 37, 236-249. [CrossRef]

36. Deb, K. Multi-Objective Optimization Using Evolutionary Algorithms; John Wiley \& Sons, Ltd.: Chichester, UK, 2001.

37. Sediqi, M.M.; Ibrahimi, A.M.; Danish, M.S.S.; Senjyu, T.; Chakraborty, S.; Mandal, P. An optimization analysis of cross-border electricity trading between Afghanistan and its neighbor countries. IFAC PapersOnLine 2018, 51, 25-30. [CrossRef]

38. Sediqi, M.M.; Furukakoi, M.; Lotfy, M.E.; Yona, A.; Senjyu, T. An optimization approach for unit commitment of a power system integrated with renewable energy sources: A case study of Afghanistan. J. Energy Power Eng. 2017, 11, 528-536.

(c) 2019 by the authors. Licensee MDPI, Basel, Switzerland. This article is an open access article distributed under the terms and conditions of the Creative Commons Attribution (CC BY) license (http:/ / creativecommons.org/licenses/by/4.0/). 